\title{
Adverse influence of multilevel socioeconomic status on physical activity: results from a national survey in Vietnam
}

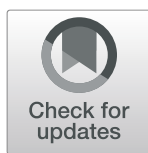

\author{
Thi Hoang Lan Vu', Thi Tu Quyen Bui ${ }^{2^{*}}$, Thi Kim Ngan Nguyen ${ }^{2}$ and Van Minh Hoang ${ }^{3}$
}

\begin{abstract}
Background: This study aims to explore associations of individual- and provincial-level socioeconomic status (SES) and the combined interaction among these SES with individual physical activity (PA).

Method: This analyze used data of 3068 Vietnamese people aged 18-65 years from the national representative STEPS survey in 2015 (STEPS2015). The survey collected PA-related data using the Global PA Questionnaire Version 2 and those on provicial-level characteristics from two surveys in 2014, namely the Intercensal Population and Housing Survey (IPHS) and The Vietnam Household Living Standard Survey (VLSS2014). Multilevel linear analyze was performed with individual and provincial characteristics as independent variables and the metabolic equivalent (MET) score - the indicator of individual PA - as the dependent variable.

Results: Male and female participants with insufficient PA accounted for 20.2 and 35.7\%, respectively. Both individual- and provicial-level SES were inversely associated with the individual PA level. As the provincial-level monthly income increased by 1 million Vietnam Dongs, the total PA score of individuals residing in that province reduced by 1900 METS. A buffering effect was reported between provincial and individual SES, as the provincial average income increased, the differences in PA scores between different SES groups decreased.

Conclusion: Our data suggest that Vietnamese individuals in low SES groups tended to be more physically active than those in high SES groups because their PA was largely related to work.
\end{abstract}

Keywords: Physical activity, Socioeconomic, Multilevel, Vietnam

\section{Background}

Physical activity (PA) has long been well documented in the literature to have important health benefits, for example strengthening bones and muscles, or reducing risks and morbidity associated with non-communicable diseases (NCDs) [1-3]. Previous studies showed that PA benefits not only physical health but also mental health as it helps reduce symptoms of anxiety or depression [4]. Evidence on health benefits of PA has been available since the 1950s;

\footnotetext{
* Correspondence: btq@huph.edu.vn

${ }^{2}$ Department of Biostatistics, Hanoi University of Public Health, No. 1A Duc Thang Ward, North Tu Liem, Ha Noi, Viet Nam

Full list of author information is available at the end of the article
}

however, the proportion of the population achieving sufficient PA remains low. According to the WHO's data in 2010, about $23 \%$ of adults aged 18 years and over were insufficiently active. Besides, the figure in high-income countries was higher than that in low-income ones [5]. Physical inactivity is among of the most important public health problems of the twenty-first century because it is responsible for $6-10 \%$ of the major NCDs and $9 \%$ of premature mortality globally [1].

Socio-economic status (SES) is a key determinant of health and well-being because it can shape a person's attitudes, practices and exposure to certain health risk factors [6]. When it comes to PA, social advantages allow

C C The Author(s). 2020 Open Access This article is licensed under a Creative Commons Attribution 4.0 International License, which permits use, sharing, adaptation, distribution and reproduction in any medium or format, as long as you give appropriate credit to the original author(s) and the source, provide a link to the Creative Commons licence, and indicate if changes were made. The images or other third party material in this article are included in the article's Creative Commons licence, unless indicated otherwise in a credit line to the material. If material is not included in the article's Creative Commons licence and your intended use is not permitted by statutory regulation or exceeds the permitted use, you will need to obtain permission directly from the copyright holder. To view a copy of this licence, visit http://creativecommons.org/licenses/by/4.0/ The Creative Commons Public Domain Dedication waiver (http://creativecommons.org/publicdomain/zero/1.0/) applies to the data made available in this article, unless otherwise stated in a credit line to the data. 
for a higher PA level [7], and more importantly, the individual PA level was even affected by the SES of his or her residential area [8].

Neighborhoods have long been recognized as the structural conditions that shape individual lives and opportunities [9]. However, in public health, the role of physical and social environments in determining individual health behaviors remains controversial $[10,11]$. Indeed, the contextual effects of neighbourhood on individual activities were mostly investigated in developed countries, and the definitions of neighbourhood varied across studies. For example, previous studies in Vietnam defined neighborhoods as administrative division such as provinces or districts. In our present study, we employed a multilevel design to explore how individual PA iss affected by individual- and provincial -level SES separately and the combined interaction among SES at different levels.

\section{Methods}

\section{Data sources}

Individual-level data: the STEPS survey 2015 was a cross-sectional survey applying the methods and tools of the WHO STEPS. The WHO Stepwise approach to surveillance (STEPS) is a simple, standardized method for collecting, analyzing and disseminating data in the World Health Organization (WHO) member countries [12]. The survey was conducted in all 63 provinces and cities of Vietnam, between June and October 2015.

Provincial-level data: data on provincial characteristics were extracted from two surveys: (1) The 2014 Intercensal Population and Housing Survey (a large sample survey implemented in the middle of two Population and Housing Censuses) and (2) The VLSS 2014.

Individual and provincial data files were linked together using the unique provincial identities (ID) in the 2009 Vietnam Population and Housing Census.

\section{Sample size}

The sample size was calculated using the WHO's sample calculator for STEPS. The samples were stratified by gender and three age groups (18-29, 30-49, and 50-69). The minimum sample size for each stratum was calculated according to the following formula:

$$
\mathrm{n}=Z^{2} \frac{P(1-P)}{e^{2}}
$$

In which $\mathrm{z}=1.96, \mathrm{e}=0.05, p=0.5$. Then considering design effect of 1.5 , an expected response rate $(80 \%)$, and the number of stratum age/sex groups (6), the total sample estimated was 4320 . With the response rate of $79.5 \%$ for all three STEP rounds, the final sample consisted of 3068 people aged 18-69 years old residing in Vietnam at the survey time.

\section{Sampling method}

A 2-stage random systematic sampling method was used. The sampling frame for the survey was developed by the General Statistics Office of Vietnam (GSO) based on the master sampling frame used in the Population and Housing Census 2009 and updated with the 2014 data [13]. Based on the Population and Housing Census data 2009 , the GSO used $15 \%$ of the master sample as the future national sampling frame for the STEPs survey. The master sample contains 25,500 enumeration areas (EAs) from 706/708 districts of Vietnam (2 island districts were excluded from the GSO master sample frame). Besides, we employed a selection probability proportional to size (PPS) sampling method, where the size calculated by dividing the selection probability of an EA from the entire target population by the selection probability of an EA from the master sample. The master sample frame of GSO was stratified by two variables: urbanization ( $1=$ urban; 2 =rural) and district group ( $1=$ district/town/city of province; 2 = plain and coastal district; 3 = mountainous, island district). In other words, it consisted of 6 sample frames (or strata). In the first stage of the sampling process, 158 EAs in the urban areas were selected for the survey, equating the number of those in the rural areas.

The second stage of sampling involved the selection of $10 \%$ of households in each EA. Thus, 15 and 14 households were respectively selected from these urban and rural EA, using a simple systematic random sampling method. Finally, STEPS 2015 recruited 4651 households, each of which had one eligible member automatically selected for the STEP 1 interview by the PDA program. The probability of selection was the product of the probabilities of selection for each stage. The sampling base weight of an eligible individual was the inverse of this selection probability.

\section{Measurement Study outcomes}

Total MET score: In the STEP survey in 2015, PArelated data were collected using the Global PA Questionnaire Version 2 (GPAQ-2) [14]. The GPAQ-2 contains 16 questions on frequency (days) and duration (minutes/hours) of moderate and vigorous-intensity PA in three domains for a typical week, namely work, transport, and recreation. The data were then converted into energy expenditure measured by Metabolic Equivalent Tasks (METS, a ratio between the working metabolic rate and the resting metabolic rate) following the instruction in the GPAQ-2 [14]. The total MET score is the sum of all METS/minutes/week from moderate-to vigorous-intensity PA in three domains.

Not meeting the WHO's PA recommendations: According to the WHO, "throughout a week, including 
activity for work, during transport and leisure time, adults should do at least an equivalent combination of moderateand vigorous-intensity PA achieving at least 600 METminutes". Therefore, a person with a total MET score of $<600$ MET-minutes in this study was defined as "not meeting the WHO's PA recommendations".

\section{Independent variables}

Subject-specific characteristics (level 1) The following demographic variables of the survey participants were evaluated: 1) gender (i.e., male/female); 2) age group (i.e., 18-29; 30-49; and 50-69 years old); 3) educational level (i.e., less than primary education, primary school, middle school, high school and university/college and higher); 4) current primary occupation (i.e., farmer, government staff and others, including housewives, small traders, temporary workers, housekeepers, handicraft makers and jobless people, etc.); 5) type of residential area (i.e., urban and rural); and 6) household economic status. We measured household economic status based on an asset-based wealth index, constructed them using principal component analysis (PCA), and divided them into quintiles (i.e., lowest, lower middle, middle, upper middle, and highest). Previous studies had suggested the use of PCA to create a proxy indicator of SES from the above items in the Vietnamese context [15].

Province-specific characteristics (level 2) The socioeconomic characteristics of 63 provinces were measured using two variables: (1) Provincial monthly income per capita: the average per capita income from all sources in 2014; and (2) Provincial urbanization rate: the percentage of the population living in urban areas in the province in 2014. That information was extracted from the VLSS 2014 [16].

\section{Statistical approach}

This study employed the approach to multilevel data analysis developed by Bryk and Raudenbush's [17]. This approach enabled us to collect data on the direct effects of individual and provincial-level factors on the total MET score and adjusted standard errors due to the effects of clustering of subject-specific measures within provinces. We designed three models as follows: 1) the first model or empty model had with no explanatory variables; 2) the second model included all individual-level variables; and 3) the third model examined variables at both individual and provincial levels. The data were extracted from the census with survey weight. We used MLwiN to analyze both scaled weighted data and unweighted data, however, weighted and unweighted data did not diverge significantly in general. To examine the contribution of provincial factors to individual total PA score, a null linear model (without any individual or school factors) was fitted, in which the provincial variance was statistically significant and accounted for 19.5\% of the total variability in individual total PA scores. Adding all individual variables to the model helped to reduce the variance at the provincial level to $13.9 \%$. In the model incorporating all individual and provincial factors (presented in Table 3), the variance at the school level still stayed significant but now only accounted for $11.8 \%$ of the variability in the outcome.

\section{Results}

\section{Characteristics of survey sample}

Table 1 shows that 3068 out of 3856 individuals completed all three STEP rounds, giving a response rate of $79.5 \%$. Females slightly outnumbered males $(57.2 \%$ vs. $42.8 \%$ ), and people aged $18-29,30-49$, and $50-69$ years accounted for $15.9,48.8$, and $46.3 \%$, correspondingly. About $62 \%$ of respondents reported being self-employed, and $68.5 \%$ had lower than secondary school education. An overwhelming proportion of the respondents belong to the Kinh group (80.2\%). The highest and lowest income groups each formed $20.0 \%$.

\section{Current situation of population physical activity}

According to Tables 2, 28.1\% of respondents did not meet the WHO's PA recommendations, i.e. the total PA score of <600 MET-minutes/ week (95\%CI: 25.9 to $30.2 \%)$. Females had a significantly lower level of PA than males. The proportion of having no recreationrelated PA was extremely high in all participants (70.6\%) and females alone (74.7\%).

Figure 1 presents the proportion of respondents not meeting the WHO's PA recommendations, by type of residential area. The proportion in urban areas (37.3, 95\%CI: 34.4-40.3\%) was much higher than that in rural areas (23.2, 95\%CI: 20.3-26.1\%).

\section{Inequities in physical activity levels across provinces}

The provincial average monthly income and the average provincial MET score varied significantly across 63 provinces in Vietnam. A negative correlation between these two factors was reported. The provinces with the lowest income per capita would be the ones with higher levels of physical activities (Fig. 2).

Multilevel model for social determinants of total MET score The multilevel model showed that both individual- and provincial-level factors had independent impacts on the individual-level total MET score. At the level 1, all demographic and socioeconomic factors were significantly associated with total MET score (Table 3). For instance, the 30-49 year-olds had a higher total MET score than the $18-29$ year-olds $(p<0.05)$, and females 
Table 1 General characteristics of the study respondents, STEPS Vietnam 2015

\begin{tabular}{|c|c|c|c|}
\hline & $\begin{array}{l}\text { Male } \\
1314(42.8 \%)\end{array}$ & $\begin{array}{l}\text { Female } \\
1754 \text { (57.2\%) }\end{array}$ & Total n (\%) \\
\hline \multicolumn{4}{|l|}{ Age group } \\
\hline $18-29$ & $219(16.7)$ & $268(15.3)$ & $487(15.9)$ \\
\hline $30-49$ & $610(46.4)$ & $887(50.60$ & $1497(48.8)$ \\
\hline $50-69$ & $485(36.9)$ & $599(34.2)$ & $1084(35.3)$ \\
\hline \multicolumn{4}{|l|}{ Residence } \\
\hline Urban & $572(43.5)$ & $803(45.8)$ & $1375(44.8)$ \\
\hline Rural & $742(56.5)$ & $951(54.2)$ & $1693(55.2)$ \\
\hline \multicolumn{4}{|l|}{ Ethnicity } \\
\hline Kinh & $1066(81.1)$ & $1443(82.3)$ & $2514(80.2)$ \\
\hline Others & 248 (18.9) & $311(17.7)$ & $566(19.8)$ \\
\hline \multicolumn{4}{|l|}{ Education } \\
\hline Primary school or less & $196(14.9)$ & $368(21.0)$ & $564(18.4)$ \\
\hline Lower secondary & $655(49.8)$ & $883(50.3)$ & $1538(50.1)$ \\
\hline Upper secondary & $245(18.6)$ & $228(13.0)$ & $473(15.4)$ \\
\hline University/college & $217(16.5)$ & $275(15.7)$ & $492(16.0)$ \\
\hline \multicolumn{4}{|l|}{ Occupation } \\
\hline Government official & $119(9.1)$ & $158(9.0)$ & $277(9.0)$ \\
\hline Non-government employee & 139 (10.6) & $145(8.3)$ & $284(9.3)$ \\
\hline Self-employed & $873(66.4)$ & $1038(59.2)$ & $1911(62.3)$ \\
\hline Student & $20(1.5)$ & $28(1.6)$ & $48(1.6)$ \\
\hline Homemaker & $9(0.7)$ & $248(14.1)$ & $257(8.4)$ \\
\hline Retired & $76(5.8)$ & $79(4.5)$ & $155(5.1)$ \\
\hline Unemployment & $78(5.9)$ & $58(3.3)$ & $136(4.4)$ \\
\hline \multicolumn{4}{|l|}{ Household economic status } \\
\hline Lowest & $252(19.2)$ & $361(20.6)$ & $613(20.0)$ \\
\hline Lower Middle & $334(25.4)$ & $468(26.7)$ & $802(26.1)$ \\
\hline Middle & $191(14.5)$ & $237(13.5)$ & $428(14.0)$ \\
\hline Upper Middle & $267(20.3)$ & $343(19.6)$ & $610(19.9)$ \\
\hline Highest & $270(20.5)$ & $345(19.7)$ & $615(20.0)$ \\
\hline
\end{tabular}

scored higher than males $(p<0.05)$. Besides, individuals with better education/ SES tended to have lower total MET scores.

At level 2, after controlling for all individual-level socioeconomic factors, the provincial-level average monthly

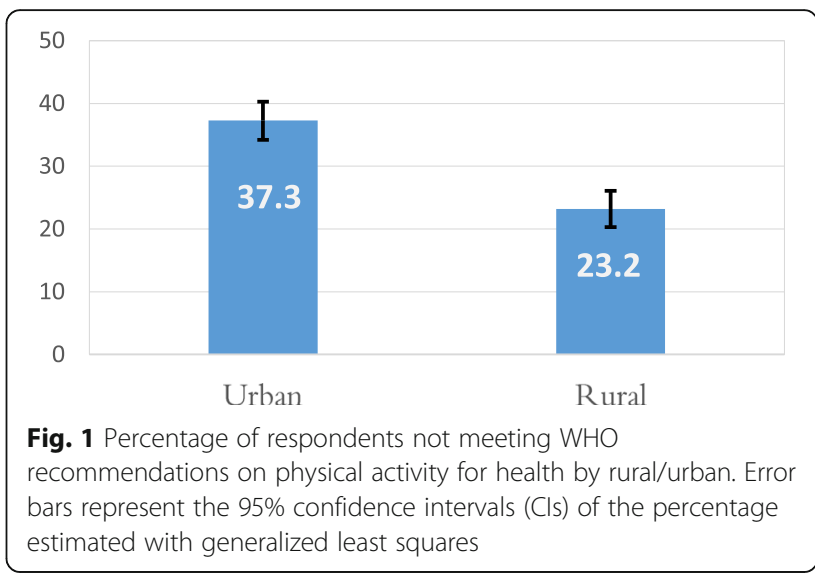

income in 2014 had a negative association with the individual total MET score $(r=-1.9)$. Particularly, as this income increased by one million dongs, the total MET score of an individual living in the province reduced by 1900 METS. A cross-level interaction was found between the individual-level SES and the provincial-level monthly income.

\section{Discussion}

This study used the data from a national representative sample of the Vietnamese population aged 16-69 years. We found that a high proportion of respondents did not meeting WHO's PA recommendations; this result is quite consistent with those in previous studies [18-23]. Besides, respondents who did not engage in recreationrelated PA accounted for the highest proportion, outnumbering those doing PA related to transportation or work. This can be explained by considering that most Vietnamese working-aged adults spend their time mainly on working, and therefore their duration of work-related PA was found longest [21, 22, 24].

This study employed a multilevel design to explore the independent impacts of individual- and provincial-level SES independently and the combined interaction among SES at different levels on individual PA. It was previously confirmed that people with higher SES tend to have better health and better lifestyles, including higher PA levels $[25,26]$. There have been reports on positive impact of the contextual SES impact on PA, as residence

Table 2 Situational analysis of physical activity among adults age 18-69-year-old in Vietnam, 2015

\begin{tabular}{|c|c|c|c|c|c|c|}
\hline & \multicolumn{2}{|l|}{ Male } & \multicolumn{2}{|c|}{ Female } & \multicolumn{2}{|c|}{ Both gender } \\
\hline & $\%$ & $95 \% \mathrm{Cl}$ & $\%$ & $95 \% \mathrm{Cl}$ & $\%$ & $95 \% \mathrm{Cl}$ \\
\hline $\begin{array}{l}\text { Percentage of respondents not meeting WHO } \\
\text { recommendations on PA for health }\end{array}$ & 20.2 & $17.8-22.6$ & 35.7 & $32.7-38.7$ & 28.1 & $25.9-30.2$ \\
\hline No work-related PA & 39.8 & $36.7-43.0$ & 56.2 & $52.7-59.6$ & 48.1 & $45.6-50.7$ \\
\hline No transport-related PA & 64.2 & $60.8-67.7$ & 50.5 & $47.2-53.8$ & 57.3 & $54.6-59.9$ \\
\hline No recreation-related PA & 66.2 & $63.1-69.4$ & 74.7 & $72.3-77.2$ & 70.6 & $68.5-72.6$ \\
\hline
\end{tabular}




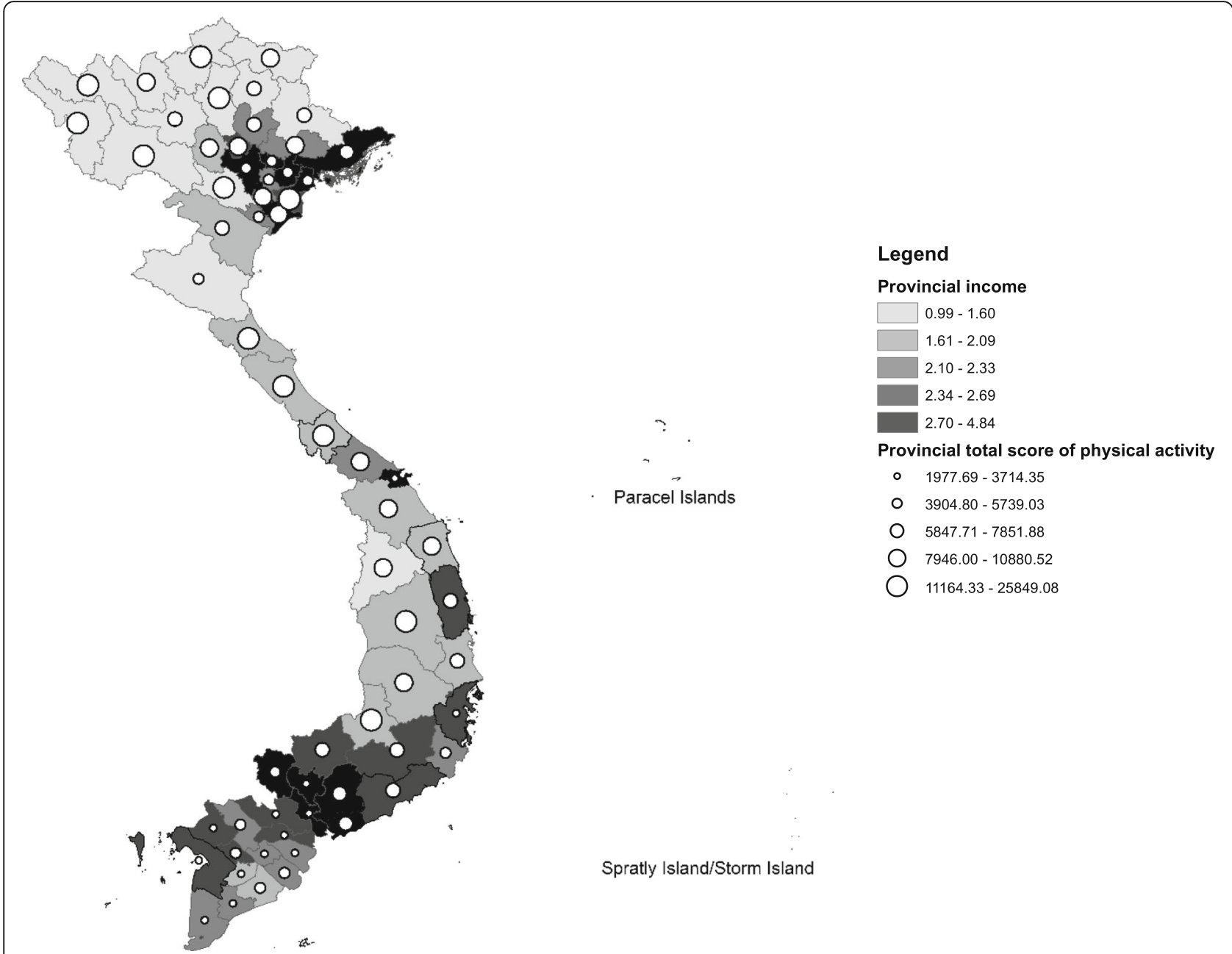

Fig. 2 Negative correlation between Provincial average physical activity score and provincial average monthly income. This map presents the correlation between the provincial average MET score and the provincial average monthly income illustrated by the shade of the polygon. The darker the shade indicates a lower income, and the size of the dots presents the mean MET score, with bigger dots indicating higher PA levels. (The map was created by the authors using ArcGIS software, with Vietnam administrative boundary shapefile and data extracted from STEPS survey and the VLSS 2014)

in a deprived neighbourhood is often associated with lower PA levels [27]. This study, however, revealed a gradient in total MET scores across all SES measures at both individual and provincial levels. In particular, individuals with higher SES tend to have lower mean PA levels. Previous studies mentioned that the association between SES and PA, whether negative or positive, largely depends on the PA domains of interest. High SES groups were more likely to do PA during leisure time whereas those with low SES tend to be involved in occupational physical activity [28, 29]. Our survey results also showed a similar trend. Indeed, more PA done by our Vietnamese study participants occurred during work and transportation than during leisure time. This contributed to explaining the adverse association between SES and PA reported in our study and the higher level of PA in low SES groups.
More interestingly, a cross-level interaction between individual and provincial SES was reported. The positive coefficients of all the interaction terms demonstrated the buffering effect of the provincial average income on the adverse impact of individual SES on total PA scores. More specifically, as the provincial average income increased, the differences in PA scores between different SES groups decreased or the adverse impact of individual SES on PA was mitigated by the provincial SES. This can be explained by the higher availability of PA resources and their higher accessibility to wealthy people in these provinces [30].

In our survey, male adults undertook more PA than females. This result has been concluded by many other authors [18-22, 24, 31, 32]. Females were less likely to participate in either vigorous-intensity (occupational) PA or sports clubs than males [33]. Vietnamese society 
Table 3 Multilevel for social - determinants of total PA scores on METS

\begin{tabular}{|c|c|c|c|c|}
\hline \multirow{2}{*}{ Fixed effects } & & \multirow[t]{2}{*}{ Null model } & \multirow[t]{2}{*}{$\begin{array}{l}\text { Model } 1 \\
\text { Coefficients (CI95\%) }\end{array}$} & \multirow[t]{2}{*}{ Model 2 Coefficients ( $\mathrm{Cl} 95 \%$ ) } \\
\hline & & & & \\
\hline \multicolumn{5}{|l|}{ Individual level } \\
\hline \multirow[t]{5}{*}{ Demographic factors } & Age 18-29 & & Ref & Ref \\
\hline & Age 30-49 & & $526.5(-0.74 ; 1053.7)$ & $573(46.1 ; 1099.8)$ \\
\hline & Age 50-69 & & $-303.1(-886.2 ; 280)$ & $-253.1(-835.8 ; 329.6)$ \\
\hline & Female vs. Male & & $-1514.2(-1874.4 ;-1153.9)$ & $-1504.6(-1864.1 ;-1145.1)$ \\
\hline & Kinh vs. other ethnics & & $-1414.8(-2027.5 ;-802.1)$ & $-1104.1(-1733.6 ;-474.5)$ \\
\hline \multirow[t]{20}{*}{ Socio-economic factors } & Education & & & \\
\hline & Primary or less & & Ref & Ref \\
\hline & Lower secondary & & $63.4(-461.9 ; 588.7)$ & $-45.0(-569.1 ; 479.1)$ \\
\hline & Upper secondary & & $-851.2(-1553.5 ;-148.9)$ & $-858.8(-1559.7 ; 157.9)$ \\
\hline & College or above & & $-971.4(-1766.6 ;-176.2)$ & $-973.6(-1767.6 ;-179.6)$ \\
\hline & Occupation & & & \\
\hline & Government employee & & Ref & Ref \\
\hline & Non-government employee & & $981.5(130.3 ; 1832.7)$ & $1024.6(173.0 ; 1876.2)$ \\
\hline & Self-employed & & $2411.2(1677.6 ; 3144.8)$ & $2384.3(1651.4 ; 3117.1)$ \\
\hline & Student & & $-409.0(-2030.1 ; 1212.1)$ & $-403.3(-2024.2 ; 1217.6)$ \\
\hline & Homemaker & & $-973.9(-1909.8 ;-38.0)$ & $-974.1(-1909.0 ;-39.2)$ \\
\hline & Retired & & $-557.6(-1581.1 ; 465.9)$ & $-564.3(-1586.8 ; 458.2)$ \\
\hline & Unemployment & & $-2803.3(-3895.6 ;-1711.0)$ & $-2708.4(-3799.7 ;-1617.1)$ \\
\hline & Rural vs. Urban & & $694.3(291.3 ; 1097.3)$ & $673.7(268.8 ; 1078.6)$ \\
\hline & Household economic status & & & \\
\hline & Lowest & & Ref & Ref \\
\hline & Lower Middle & & $-552.0(-1107.5 ; 3.5)$ & $-3149.6(-5000.4 ;-1298.8)$ \\
\hline & Middle & & $-1308.5(-1966.9 ;-650.1)$ & $-3934(-6090.6 ;-1777.4)$ \\
\hline & Upper Middle & & $-1492.6(-2141.4 ;-843.8)$ & $-4766.1(-6777.3 ;-2754.9)$ \\
\hline & Highest & & $-1963.4(-2667.6 ;-1259.2)$ & $-5299.9(-7377.1 ;-3222.7)$ \\
\hline \multicolumn{5}{|l|}{ Provincial-level } \\
\hline \multicolumn{2}{|c|}{ Provincial urbanization rate in 2014} & & & $-13(-51.2 ; 25.2)$ \\
\hline \multicolumn{2}{|c|}{ Provincial average income per capital in 2014} & & & $-1.9(-3.1 ;-0.7)$ \\
\hline \multicolumn{5}{|c|}{$\begin{array}{l}\text { Interaction between individual SES and } \\
\text { provincial average income per capita }\end{array}$} \\
\hline \multicolumn{2}{|c|}{ Between middle low and average income } & & & $1.3(0.5 ; 2.1)$ \\
\hline \multicolumn{2}{|c|}{ Between middle and average income } & & & $1.3(0.3 ; 2.3)$ \\
\hline \multicolumn{2}{|c|}{ Between middle high and average income } & & & $1.6(0.8 ; 2.4)$ \\
\hline \multicolumn{2}{|c|}{ Between high and average income } & & & $1.6(0.8 ; 2.4)$ \\
\hline \multicolumn{5}{|l|}{ Random effects } \\
\hline \multicolumn{2}{|l|}{ Province (variance) } & $6,712,211$ & $3,612,203$ & $2,974,521$ \\
\hline \multicolumn{2}{|l|}{ Individual (variance) } & $27,710,766$ & $22,321,687$ & $22,245,934$ \\
\hline \multicolumn{2}{|l|}{ ICC (\%) } & 19.5 & 13.93 & 11.79 \\
\hline \multicolumn{2}{|c|}{ Change in -2loglikelihood } & & $691(\mathrm{df}=19)$ & $21(d f=5)$ \\
\hline
\end{tabular}


places household responsibilities on women; hence, they devote their time to doing household chores and taking care of children while spending less time on sports activities than men do. Besides, male adults are more likely to take part in transport-related PA such as walking and cycling because they are more active and have more comfortable clothing [31].

Our findings, like those of many other studies [20, 21, 34], show that urban dwellers were less involved in PA than those living in rural areas. A possible explanation for this is that people living in urban areas are more likely to work in offices and therefore adopt a sedentary lifestyle. Rural residents were more likely to be involved in labor-intensive jobs (e.g. farming or fishing) that require more vigorousintensity PA. As a result, they had a higher total MET score than urban dwellers.

Like some other studies [21, 24, 28, 34, 35], our study pound that individuals with higher levels of education tended to participate in more PA than those with lower levels of education. The former had jobs that require mental labor or worked as white-collar workers Another finding of our study is similar to Stalsberg's [28] in that both indicate that free workers (often, but not necessarily, having lower education), were largely blue-collar workers and those with comparatively low skill levels. They might be more involved in PA than government employees. In certain studies, better-educated individuals were more likely to engage in exercise/ sports during leisure time than those with lower educational achievement. However, their daily tasks at work tended to be more sedentary. Because they mainly participated in work-related PA (as mentioned above), their total MET score was lower than those with lower education levels. Therefore, education is a factor that helps in assessing the duration of each individual PA domain (such as leisure-time or occupational PA); however, it is of no use in estimating the duration of total PA.

Vietnam has 54 ethnic groups, among which the Kinh ethnic group accounted for more than $80 \%$ of the national population. The Kinh people are considered the most developed group, and most of them reside in the most advantaged regions in Vietnam. In our study, this group participated in PA less than the ethnic minority groups. Our study result is consistent with that in a study by Chang Ying [21] and another by Trinh et al. [22]. As ethnic minority people live in remote and mountainous areas, they are more likely to engaged in PA (e.g. walking up and down hills/mountains, bicycling, or doing farm work). Meanwhile, the Kinh ethnic group with better education are more likely to do mental jobs.

In our study, individuals aged 30-49 years were more likely to participate in PA. They dominated labor force; therefore, it is undoubted that they had the highest intensity of PA. As PA is highly associated with work, the working-age population is more likely to do PA. However, some authors such as Hallal et al. [18] revealed that older age was associated with reduced total PA. Considering each PA domain, some other authors found that older adults had higher leisure-time PA than children because the former had more leisure time, were more interested in doing PA for the sake of their health, and could afford leisure-time PA.

\section{Strengths and limitations}

Our study had a number of strengths. The high response rates, the national samples and the multistage clustered random selection of samples help to ensure that the data were nationally representative. Another strength of this study was the large-scale sample selected from the whole country's population. The GPAQ was used to identify the level of PA in the three domains and provide more information about the trends in the PA level of Vietnamese citizens. However, our study also encountered some limitations such as recall bias and inaccurate estimation which were inevitable due to self-report of PA levels. The level of PA was over-estimated due to recall bias, and the study respondents might give socially accepted answers other than those reflecting what they "really" thought (social desirability bias).

Previous studies advocated for assessment of total PA [36]. However, other also suggested that the sub-domain of PA (i.e., leisure PA or occupational PA) may have different impacts on health and should be considered separately [37]. This study analyzed secondary data from the national survey that used the GPAQ to collect PA-related information. The GPAQ only applies to the assessment of total PA, but not to each domain [38]. Future studies may need to analyze leisure-time and occupational PA separately in order to present a comprehensive picture of the level of PA in the general Vietnamese population.

\section{Conclusions}

As PA domains may have different determinants and directions of association with SES, examining them in the studied population is of great importance. The study reported a negative association between SES and PA because most PA of the Vietnamese population was work-related; low SES groups came out as more active. Future studies should examine PA domains separately to provide practitioners with further recommendations on low/high SES populations in developing countries.

\section{Abbreviations}

GPAQ: Global PA Questionnaire; GSO: General Statistics Office; METS: Metabolic Equivalent Tasks; MOH: Ministry of Health; PA: Physical activity; PCA: Principal component analysis; SES: Social-economic status; STEPS: Stepwise approach to Surveillance; VLSS: The Vietnam household living standard survey 


\section{Acknowledgements}

The authors would like to give our special thanks to Vietnam's Ministry of Health $(\mathrm{MOH})$ for providing us with free access to the data set of STEPS 2015.

\section{Authors' contributions}

Lan and Quyen led the design and conceptualization of the study, as well as the reporting of results. Lan, Quyen and Ngan performed the analyses and contributed to the written manuscript. Minh also contributed to the article by refining the manuscript. All authors read and approved the final manuscript.

\section{Funding}

The authors have not received any funding or benefits from industry or elsewhere to write this paper because we have used secondary data for writing the manuscript.

\section{Availability of data and materials}

The datasets used and/ or analyzed during the current study were from the STEPs 2015 survey which are available from General Department of Preventive Medicine, Ministry of Health, Vietnam upon contact dp@moh.gov. vn on reasonable request.

\section{Ethics approval and consent to participate}

This paper was based on secondary data from the STEPs 2015 with all identifying information removed. All procedures performed in STEPS2015 involving human participants were in accordance with the ethical standards of The Ethical Review Board for Biomedical Research Hanoi University of Public Health. All information on the original dataset was collected confidentially.

\section{Consent for publication}

Not applicable.

\section{Competing interests}

The authors declare that they have no competing interests.

\section{Author details}

'Department of Epidemiology, Hanoi University of Public Health, No. 1A Duc Thang Ward, North Tu Liem, Ha Noi, Viet Nam. ${ }^{2}$ Department of Biostatistics, Hanoi University of Public Health, No. 1A Duc Thang Ward, North Tu Liem, Ha Noi, Viet Nam. ${ }^{3}$ Hanoi University of Public Health, No. 1A Duc Thang Ward, North Tu Liem, Ha Noi, Viet Nam.

\section{Received: 14 October 2019 Accepted: 13 April 2020}

\section{Published online: 25 April 2020}

\section{References}

1. Lee IM, Shiroma EJ, Lobelo F, et al. Impact of Physical Inactivity on the World's Major Non-Communicable Diseases. Lancet. 2012;380(9838):219-29. https://doi.org/10.1016/s0140-6736(12)61031-9 PubMed PMID: 22818936; PubMed Central PMCID: PMCPMC3645500. eng.

2. Booth FW, Laye MJ, Roberts CK. Lack of exercise is a major cause of chronic diseases. Compr Physiol. 2012;2(2):1143-211. https://doi.org/10.1002/cphy. c110025 PubMed PMID: 23798298; PubMed Central PMCID: PMCPMC4241367. eng.

3. Santos L, Elliott-Sale KJ, Sale C. Exercise and bone health across the lifespan. Biogerontology. 2017:18(6):931-46. https://doi.org/10.1007/s10522-017-97326 PubMed PMID: 29052784; PubMed Central PMCID: PMCPMC5684300. eng.

4. Saxena S, Van Ommeren M, Tang KC, et al. Mental health benefits of physical activity. J Mental Health. 2005;14(5):445-51. https://doi.org/10.1080/ 09638230500270776

5. World Health Organization. http://www.who.int/news-room/fact-sheets/ detail/physical-activity

6. Huurre T, Aro H, Rahkonen O. Well-being and health behaviour by parental socioeconomic status: a follow-up study of adolescents aged 16 until age 32 years. Soc Psychiatr Psychiatric Epidemiol. 2003;38(5):249-55. https://doi. org/10.1007/s00127-003-0630-7 PubMed PMID: 12719840; eng.

7. Bolívar J, Daponte A, Rodríguez M, et al. The influence of individual, social and physical environment factors on physical activity in the adult population in Andalusia, Spain. Int J Environ Res Public Health. 2010;7(1):6077. https://doi.org/10.3390/ijerph7010060 PubMed PMID: 20195433; eng.

8. Schüle SA, Bolte G. Interactive and Independent Associations between the Socioeconomic and Objective Built Environment on the Neighbourhood Level and Individual Health: A Systematic Review of Multilevel Studies. PLoS ONE. 2015;10(4):e0123456. https://doi.org/10.1371/journal.pone.0123456 04/ 0708/06/received; 03/03/accepted PubMed PMID: PMC4388459.

9. Massey D, Gross A, Eggers M. Segregation, the concentration of poverty, and the life chances of individuals. Soc Sci Res. 1991;20:397-420.

10. Schwartz $\mathrm{S}$. The fallacy of the ecological fallacy-the potential misuse of a concept and the consequences. Am J Public Health. 1994;84(5):819-24.

11. Macintyre S, Maciver S, Sooman A. Area, class, and health: should we be focusing on places or people? I Soc Policy. 1993;22:213-34.

12. World Health Organization. STEPwise approach to surveillance (STEPS) [cited 2018 Sep 6]. Available from: http://www.who.int/chp/steps/en/.

13. Ministry of Health. National survey on the risk factors of non-Cummunicable Disases (STEPS) Viet Nam, 2015. Ha Noi: General Department of Preventive Medicine; 2016

14. Global Physical Activity Questionnaire [Internet]. https:/www.who.int/ncds/ surveillance/steps/GPAQ/en/. [cited Jan 08, 2019]. Available from: https:// www.who.int/ncds/surveillance/steps/GPAQ/en/.

15. Vu L, Tran B, Le A. The Use of Total Assets as a Proxy for Socioeconomic Status in Northern Vietnam. Asia Pac J Public Health. 2011;23(6):996-1004.

16. General statistics office. Results of the Viet Nam household living standards survey 2014. Hanoi: Statistical publishing house; 2016.

17. Bryk A. S R. Hierarchichal linear models: applications and data analysis methods. Newbury Park: Sage; 1992.

18. Hallal PC, Andersen LB, Bull FC, et al. Global physical activity levels: surveillance progress, pitfalls, and prospects. Lancet. 2012 Jul 21;380(9838):247-57. https:// doi.org/10.1016/S0140-6736(12)60646-1 PubMed PMID: 22818937.

19. Kahan D. Adult physical inactivity prevalence in the Muslim world: Analysis of 38 countries. Preventive Medicine Reports, vol. 2; 2015. p. 71-5. https:// doi.org/10.1016/.jpmedr.2014.12.007.

20. Sharara E, Akik C, Ghattas H, et al. Physical inactivity, gender and culture in Arab countries: a systematic assessment of the literature. BMC Public Health 2018:18. https://doi.org/10.1186/s12889-018-5472-z PubMed PMID: 2049670716; English

21. Ying C, Kuay LK, Huey TC, et al. Prevalence and factors associated with physical inactivity among Malaysian adults. Southeast Asian J Trop Med Public Health 2014:45(2):467-480. 2017-03-19PubMed PMID: 1524844330; 24968689; English.

22. Trinh OT, Nguyen ND, Dibley MJ, et al. The prevalence and correlates of physical inactivity among adults in Ho Chi Minh City [journal article]. BMC Public Health. 2008;8(1):204. https://doi.org/10.1186/1471-2458-8-204.

23. Lee $S A, X u W H$, Zheng $W$, et al. Physical activity patterns and their correlates among Chinese men in Shanghai. Med Sci Sports Exerc. 2007; 39(10):1700-7. https://doi.org/10.1249/mss.0b013e3181238a52 PubMed PMID: 17909395

24. Vaidya A, Krettek A. Physical activity level and its sociodemographic correlates in a peri-urban Nepalese population: a cross-sectional study from the Jhaukhel-Duwakot health demographic surveillance site. Int J Behav Nutr Phys Act. 2014;11(1):39. https://doi.org/10.1186/1479-5868-11-39 PubMed PMID: 24628997: PubMed Central PMCID: PMCPMC3984675.

25. Zhang $X$, Martinez-Donate AP. Socioeconomic status and youth physical fitness: evidence from an upper-middle income country. J Pediatr. 2017:185: 14-6. https://doi.org/10.1016/j.jpeds.2017.02.001 PubMed PMID: 28233550.

26. Abou Elmagd M, Sami M, El-Marsafawy T, et al. The effect of socioeconomic status on the effective students' participation in physical activity: a cross sectional study from Ras Alkhaimah medical and health Sciences University-UAE. Vol. 2016;2016

27. Lee RE, Cubbin C, Winkleby M. Contribution of neighbourhood socioeconomic status and physical activity resources to physical activity among women. J Epidemiol Community Health. 2007;61(10):882-90. https:// doi.org/10.1136/jech.2006.054098 PubMed PMID: 17873224

28. Stalsberg R, Pedersen AV. Are Differences in Physical Activity across Socioeconomic Groups Associated with Choice of Physical Activity Variables to Report? Int J Environ Res Public Health. 2018;15(5). https://doi.org/10. 3390/ijerph15050922 PubMed PMID: 29734745: PubMed Central PMCID: PMCPMC5981961

29. Beenackers MA, Kamphuis CBM, Giskes K, et al. Socioeconomic inequalities in occupational, leisure-time, and transport related physical activity among 
European adults: A systematic review. Int I Behav Nutr Physical Activity. 2012. https://doi.org/10.1186/1479-5868-9-116 20122014-03-08:9:116 . PubMed PMID: 1139002711; 22992350; English.

30. Chinn DJ, White M, Harland J, et al. Barriers to physical activity and socioeconomic position: implications for health promotion. J Epidemiol Community Health 1999;53(3):191-192. PubMed PMID: 10396499.

31. Talaei M, Rabiei K, Talaei Z, et al. Physical activity, sex, and socioeconomic status: A population based study. ARYA Atheroscler. 2013;9(1):51-60 PubMed PMID: 23696760; PubMed Central PMCID: PMCPMC3653259.

32. Azevedo MR, Araujo CL, Reichert FF, et al. Gender differences in leisure-time physical activity. Int J Public Health. 2007;52(1):8-15. PubMed PMID: 17966815; PubMed Central PMCID: PMCPMC2778720

33. Deaner RO, Geary DC, Puts DA, et al. A sex difference in the predisposition for physical competition: males play sports much more than females even in the contemporary U.S. PLoS One. 2012:7(11):e49168. doi: https://doi.org/ 10.1371/journal.pone.0049168. PubMed PMID: 23155459; PubMed Central PMCID: PMCPMC3498324.

34. Bauman A, Ma G, Cuevas F, et al. Cross-national comparisons of socioeconomic differences in the prevalence of leisure-time and occupational physical activity, and active commuting in six Asia-Pacific countries. J Epidemiol Community Health. 2011;65(1):35. https://doi.org/10. 1136/jech.2008.086710.

35. Brown H, Roberts J. Exercising choice: The economic determinants of physical activity behaviour of an employed population. Social Science \& Medicine. 2011 2011/08/01/;73(3):383-390. doi: https://doi.org/10.1016/j. socscimed.2011.06.001.

36. Blair SN, Cheng Y, Holder JS. Is physical activity or physical fitness more important in defining health benefits? Med Sci Sports Exerc. 2001 Jun;33(6 Suppl):S379-99; discussion S419-20. doi: https://doi.org/10.1097/00005768200106001-00007. PubMed PMID: 11427763

37. Holtermann A, Krause N, van der Beek AJ, et al. The physical activity paradox: six reasons why occupational physical activity (OPA) does not confer the cardiovascular health benefits that leisure time physical activity does. Br J Sports Med. 2018;52(3):149. https://doi.org/10.1136/bjsports-2017097965.

38. Cleland CL, Hunter RF, Kee F, et al. Validity of the Global Physical Activity Questionnaire (GPAQ) in assessing levels and change in moderate-vigorous physical activity and sedentary behaviour. BMC Public Health. 2014 2014/12/ 10;14(1):1255. doi: https://doi.org/10.1186/1471-2458-14-1255.

\section{Publisher's Note}

Springer Nature remains neutral with regard to jurisdictional claims in published maps and institutional affiliations.

Ready to submit your research? Choose BMC and benefit from:

- fast, convenient online submission

- thorough peer review by experienced researchers in your field

- rapid publication on acceptance

- support for research data, including large and complex data types

- gold Open Access which fosters wider collaboration and increased citations

- maximum visibility for your research: over $100 \mathrm{M}$ website views per year

At BMC, research is always in progress.

Learn more biomedcentral.com/submissions 